\title{
Insularinase A, a prothrombin activator from Bothrops insularis venom, is a metalloprotease derived from a gene encoding protease and disintegrin domains
}

\author{
Jeanne Claíne de Albuquerque Modesto', \\ Inácio Loióla Meireles Junqueira-de-Azevedo², \\ Ana Gisele C. Neves-Ferreira ${ }^{3}$, Márcio Fritzen', \\ Maria Luíza Vilela Oliva4, Paulo Lee $\mathrm{Ho}^{2,5}$, \\ Jonas Perales ${ }^{3}$ and Ana Marisa Chudzinski- \\ Tavassi ${ }^{1, *}$ \\ ${ }^{1}$ Laboratório de Bioquímica e Biofísica, Instituto \\ Butantan, Av. Vital Brazil 1500, 05503-900 São Paulo, \\ SP, Brazil \\ ${ }^{2}$ Centro de Biotecnologia, Instituto Butantan, Av. Vital \\ Brazil 1500, 05503-900 São Paulo, SP, Brazil \\ ${ }^{3}$ Departamento de Fisiologia e Farmacodinâmica, \\ Instituto Osvaldo Cruz-Fiocruz, Rio de Janeiro 21045- \\ 900, RJ, Brazil \\ ${ }^{4}$ Departamento de Bioquímica, Universidade Federal de \\ São Paulo, São Paulo 0550801, SP, Brazil \\ ${ }^{5}$ Instituto de Biociências e Instituto de Química da \\ Universidade de São Paulo, São Paulo 0550801, SP, \\ Brazil \\ ${ }^{*}$ Corresponding author \\ e-mail: amchudzinski@butantan.gov.br
}

\begin{abstract}
The first low-molecular-mass metalloprotease presenting prothrombin activating activity was purified from Bothrops insularis venom and named insularinase $A$. It is a single-chain protease with a molecular mass of $22639 \mathrm{Da}$. cDNA sequence analysis revealed that the disintegrin domain of the precursor protein is post-translationally processed, producing the mature insularinase A. Analysis of its deduced amino acid sequence showed a high similarity with several fibrin(ogen)olytic metalloproteases and only a moderate similarity with prothrombin activators. However, SDS-PAGE of prothrombin after activation by insularinase $A$ showed fragment patterns similar to those generated by group A prothrombin activators, which convert prothrombin into meizothrombin independently of the prothrombinase complex. In addition, insularinase $A$ activates factor $X$ and hydrolyses fibrinogen and fibrin. Chelating agents fully inhibit all insularinase A activities. Insularinase A induced neither detachment nor apoptosis of human endothelial cells and was also not able to trigger an endothelial proinflammatory cell response. Nitric oxide and prostacyclin levels released by endothelial cells were significantly increased after treatment with insularinase $A$. Our results show that, although its primary structure is related to class $\mathrm{P}-\mathrm{I}$ fibrin(ogen)olytic metalloproteases, insularinase $A$ is functionally similar to group A prothrombin activators.
\end{abstract}

Keywords: Bothrops insularis; coagulation; endothelial cell; metalloprotease; prothrombin activator; snake venom.

\section{Introduction}

The human blood coagulation system comprises a series of linked glycoproteins that upon activation induce the generation of downstream enzymes ultimately forming fibrin. Thrombin plays a central role in blood coagulation and therefore the rate of thrombin generation and the total amount of thrombin formed provide a good estimate of the potential coagulation activity (Spronk et al., 2003). Prothrombin activators are present in the venom of a large number of different snake species and can be classified into four different groups based on their structural and functional properties (Kini et al., 2001). Group A corresponds to metalloproteases with actions on prothrombin independent of any plasma or exogenous cofactors. Group B is composed of $\mathrm{Ca}^{+2}$-dependent metalloproteases. These groups are widely distributed in venoms of many kinds of viper, e.g., genera Echis and Bothrops, and are presumably the most toxic, since they are resistant to the natural coagulation inhibitors (serpins) present in mammalian plasma, such as antithrombin-III (Rosing and Tans, 1992). Group C activators are serine proteases that require $\mathrm{Ca}^{+2}$ ions and negatively charged phospholipids for maximal activity. Group D comprises serine proteases with structures and functions homologous to blood coagulation factors and activity strongly stimulated by $\mathrm{Ca}^{+2}$ ions, factor $\mathrm{Va}$ and negatively charged phospholipids (Kini et al., 2001). The prothrombin-activating metalloproteases already purified from the venoms of $B$. erythromelas, $B$. asper, $B$. neuwiedi and $B$. atrox convert prothrombin into meizothrombin, independently of the prothrombinase complex components, having been classified as group A prothrombin activators. All of them are single-chain proteases of high molecular mass (60-78 kDa), classified as P-III metalloproteases (GoversRiemslag et al., 1987; Hofmann and Bon, 1987; Loria et al., 2003; Silva et al., 2003).

Snake venom metalloproteinases (SVMPs) are members of the reprolysin family (MEROPS family M12 subfamily adamalysin) of zinc-containing metalloproteinases and are grouped into four classes (P-I to P-IV) according to their domain structure (Bjarnason and Fox, 1995). The $\mathrm{P}-\mathrm{I}$ class presents only the metalloprotease domain. In the P-II class, the protease domain is followed by a disintegrin domain. Class P-III enzymes are composed of protease and disintegrin-like and cysteine-rich domains. The $\mathrm{P}-\mathrm{IV}$ class has a lectin-like domain in addition to the previously described domains (Jia et al., 1996; Gutiérrez and 
A
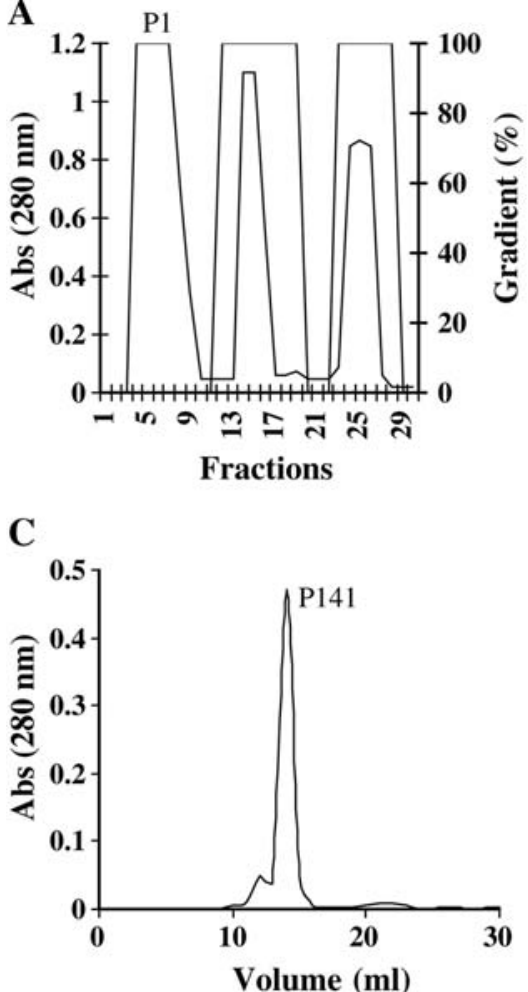

B

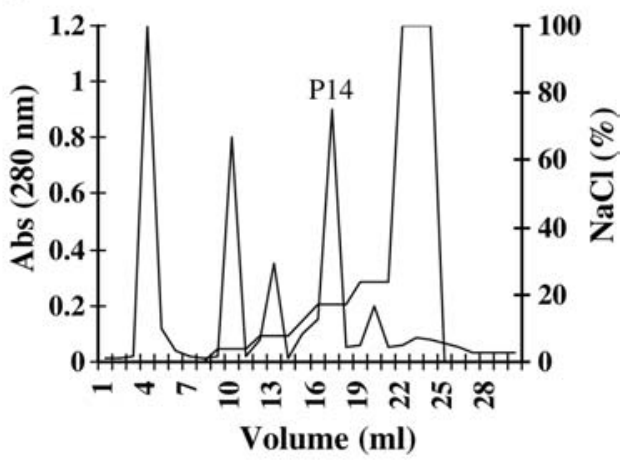

D

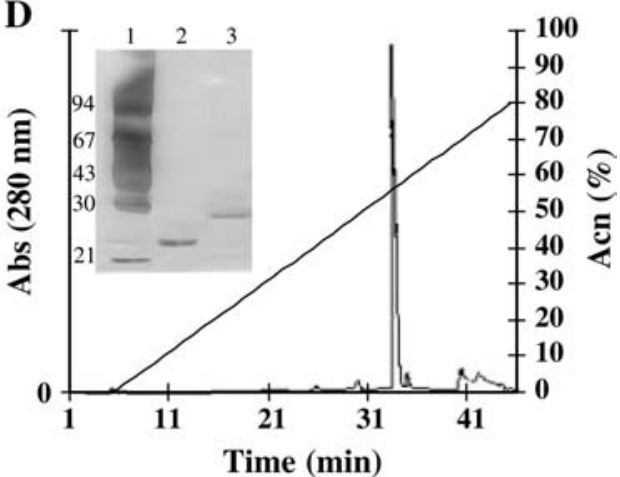

Figure 1 Purification of insularinase A.

(A) Affinity chromatography of $B$. insularis venom $(50 \mathrm{mg})$ on a benzamidine Sepharose $6 \mathrm{~B}$ column equilibrated with $0.02 \mathrm{M}$ phosphate buffer, $\mathrm{pH} 7.8$ and eluted with $0.02 \mathrm{M}$ phosphate buffer, $\mathrm{pH} 7.8$, and the same buffer containing $0.5 \mathrm{M} \mathrm{NaCl}$ and $0.02 \mathrm{M}$ glycine buffer, $\mathrm{pH}$ 3.2. (B) lon-exchange chromatography of $\mathrm{P} 1$ on a Resource $\mathrm{S}$ column equilibrated with $0.05 \mathrm{M} \mathrm{MES}$ buffer, $\mathrm{pH} 6.0$ and eluted with a gradient of $0-1 \mathrm{M} \mathrm{NaCl}$. (C) Gel filtration chromatography of P14 on Superdex 200 column equilibrated with $0.05 \mathrm{M}$ Tris- $\mathrm{HCl}$ buffer, pH 8.0. (D) Reversed-phase HPLC of insularinase A (100 $\mu \mathrm{g})$ on a C8 column equilibrated with solvent A (0.1\% TFA in water) and eluted with a $0-80 \%$ gradient of solvent B (acetonitrile/solvent A, 9:1 v/v). Inset: SDS/PAGE of insularinase A (10 $\mu$ g) under nonreducing (lane 2) and reducing conditions (lane 3). Lane 1, molecular mass markers (phosphorylase b, $94 \mathrm{kDa}$; albumin, $67 \mathrm{kDa}$; ovoalbumin, $43 \mathrm{kDa}$; carbonic anhydrase, $30 \mathrm{kDa}$; trypsin inhibitor, $21 \mathrm{kDa}$ ).

Rucavado, 2000). In general, P-II metalloproteases are proteolytically processed by autocatalysis or by other proteases, generating disintegrins and P-I metalloproteases. Although the exact site of proteolysis is variable, this processing always occurs within the spacer region, located between the protease and the disintegrin domains. Atrolysin E and HR2a hemorrhagic enzymes isolated from Crotalus atrox and Trimeresurus flavoviridis venoms, respectively, are examples of P-I metalloproteases produced as a result of the processing of its P-II metalloprotease precursors (Shimokawa et al., 1997; Yamada et al., 1999). Interestingly, mature P-II metalloproteases are rarely found in snake venoms, and the first findings have been published relatively recently (Nikai et al., 2000; Chen et al., 2003).

Bothrops insularis (jararaca ilhoa) is a dangerous viperid snake restricted to Queimada Grande Island, located off the São Paulo State coast (Brazil). In contrast to other bothropic snakes, its diet consists of birds and some invertebrates as a result of the absence of mammals on this island. Consequently, $B$. insularis venom may present some specific toxins selected to better capture its prey (Duarte et al., 1995). Recently, Junqueira-de-Azevedo and Ho (2002) reported the analysis of expressed sequence tags (ESTs) generated from the cDNA library for $B$. insularis venom glands. According to the authors, the metalloproteases are the most diversified and expressed group of proteins in this venom.

In this report, we describe the isolation, cDNA sequence, primary structure and biological specificity of the first P-I SVMP with prothrombin activating activity purified from $B$. insularis venom, named insularinase $A$. This metalloprotease is generated upon cleavage of its precursor, a class P-II metalloprotease.

\section{Results}

\section{Purification of insularinase A}

Prothrombin and factor $\mathrm{X}$ activating activities and lysis of fibrin plate were obtained in the unbound peak (P1) from the benzamidine Sepharose 6B column (Figure 1A). P1 was then fractionated on a Resource-S chromatography column into a major peak eluting just before the end of the gradient, and four other peaks (Figure 1B). Pool P14 containing prothrombin activating activity was submitted to a further chromatography on a Superdex 200 column, revealing the major peak P141 (Figure 1C). The purity of P141 was demonstrated by RP-HPLC on a C8 column, resulting in a homogeneous peak eluted at a retention time of $34 \mathrm{~min}$. The purified active protein (P141) was then named insularinase A (Figure 1D). 
M I $Q$

1 CATAGTCAACAGAGGAAGAGCTCAGATTGGCTTGAAAGAAGGAAGAGATTGCCTGTCTTCCAGCCAAATCCAACCTCCAAAATGATCCAG $\begin{array}{llllllllllllllllllllllllllllllll}V & L & \text { L } & \text { V } & \text { T } & \text { I } & C & \text { C } & A & A & \text { F } & \text { P } & \text { Y } & \text { Q } & G & \text { S } & \text { S } & \text { I } & \text { I } & \text { L } & \text { E } & \text { S } & G & \text { N } & \text { V } & \text { N } & \text { D } & \text { Y } & \text { E } & \text { V }\end{array}$ 91 GTTCTCTTGGTAACTATATGCTTAGCAGCTTTTCCTTATCAAGGGAGCTCTATAATCCTGGAATCTGGGAACGTGAATGATTATGAAGTA $\begin{array}{llllllllllllllllllllllllllllllllll}V & Y & A & R & K & V & T & E & L & P & K & G & A & V & Q & Q & K & Y & E & D & A & M & Q & Y & E & F & K & V & N & G\end{array}$ 181 GTCTATGCACGAAAAGTCACTGAATTGCCCAAAgGAGCAGTTCAGCAAAAGTATGAAGATGCCATGCAATATGAATTTAAAGTGAATGGA $\begin{array}{lllllllllllllllllllllllllllllll} & \mathrm{P} & \mathrm{P} & \mathrm{V} & \mathrm{V} & \mathrm{L} & \mathrm{H} & \mathrm{L} & \mathrm{E} & \mathrm{K} & \mathrm{N} & \mathrm{K} & \mathrm{G} & \mathrm{L} & \mathrm{F} & \mathrm{S} & \mathrm{E} & \mathrm{D} & \mathrm{Y} & \mathrm{S} & \mathrm{E} & \mathrm{T} & \mathrm{H} & \mathrm{Y} & \mathrm{S} & \mathrm{P} & \mathrm{D} & \mathrm{G} & \mathrm{R} & Q & \mathrm{I}\end{array}$ 271 GAGCCAGTGGTCCTTCACCTGGAAAAAAATAAAGGACTTTTTTCAGAAGATTACAGCGAGACTCATTATTCCCCTGATGGCAGACAAATT $\begin{array}{lllllllllllllllllllllllllllllllllll}I & T & Y & P & P & F & E & D & H & C & Y & Y & H & G & R & I & E & N & D & A & D & S & T & A & S & I & S & A & C & N\end{array}$ 361 ATAACATACCCCCCATTTGAGGATCACTGCTATTATCATGGACGCATCGAGAATGATGCTGACTCAACTGCAAGCATCAGTGCATGCAAC

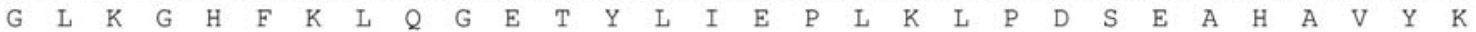
451 GGTTTGAAAGGACATTTCAAGCTTCAAGGGGAGACGTACCTTATTGAACCCTTGAAGCTTCCCGACAGTGAAGCCCATGCAGTCTACAAA

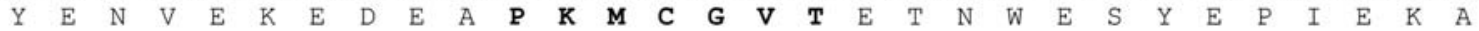
541 TATGAAAACGTAGAAAAAGAGGATGAGGCCCCCAAAATGTGTGGAGTAACTGAGACTAATTGGGAATCATATGAGCCCATCGAAAAGGCC $\begin{array}{lllllllllllllllllllllllllllllllllll}S & Q & S & N & L & T & P & E & Q & Q & K & F & S & P & R & Y & I & E & L & A & V & V & A & D & H & G & M & F & T & K\end{array}$ 631 TCTCAGTCAAATCTTACTCCTGAACAACAAAAATTCTCCCCAAGATACATTGAGCTTGCTGTAGTTGCAGATCACGGAATGTTCACGAAA $\begin{array}{lllllllllllllllllllllllllllllllll}Y & N & S & N & L & N & T & I & R & T & R & V & H & E & M & V & N & T & L & N & G & F & F & R & S & V & N & V & D & A\end{array}$ TACAACAGCAATTTAAATACTATAAGAACACGGGTACATGAAATGGTCAACACTCTAAATGGGTTTTTCAGATCTGTGAATGTTGATGCA

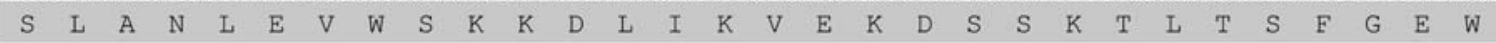
TCACTGGCTAACCTAGAAGTTTGGTCCAAGAAAGATTTGATCAAAGTGGAGAAAGATTCAAGTAAAACTTTGACGTCATTTGGAGAATGG

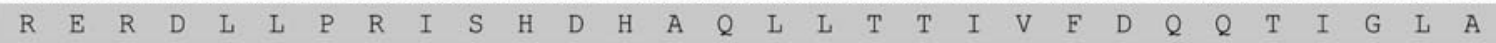
AGAGAGAGAGATTTGCTGCCTCGCATAAGTCATGATCATGCTCAGTTACTCACGACCATTGTCTTCGATCAACAAACTATAGGATTAGCT

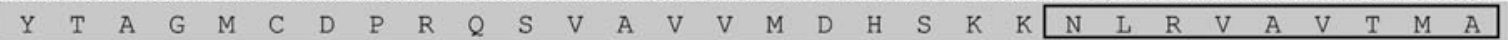
TACACAGCTGGCATGTGCGACCCGAGGCAATCTGTAGCAGTTGTTATGGATCATAGTAAAAAAAATCTTCGGGTTGCAGTTACAATGGCC

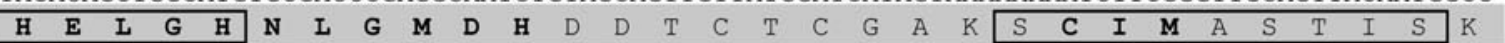
CATGAGCTGGGTCATAATCTGGGCATGGATCATGACGATACCTGTACTTGCGGTGCTAAGTCATGTATTATGGCTTCCACAATAAGCAAA

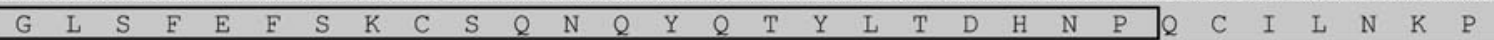
GGACTTTCCTTTGAGTTCAGCAAATGTAGTCAGAATCAATATCAGACGTATCTTACTGATCATAACCCACAATGCATTCTCAATAAACCC

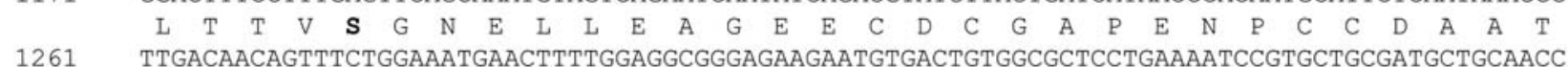

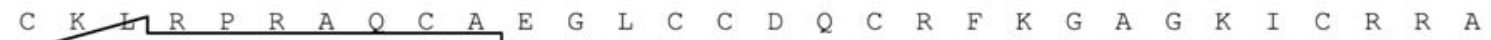
1351 TGAACTGAGACCAAGGGCGCAGTGTGCA GAAGGACT GTGTTGTGACCAGTGCAGATTTAAGGGAGCAGGAAAAATATGCCGGAGAGCA $\begin{array}{llllllllllllllllllllllllllllllllllll}R & G & D & N & P & D & D & R & C & T & G & Q & S & A & D & C & P & R & N & R & F & H & A\end{array}$

1441 AGGGGTGATAACCCGGATGATCGCTGCACTGGCCAATCTGCTGACTGTCCCAGAAATCGCTTCCATGCCTAACCAACAATGGAGATGGAA 1531 TGGTCTGCAGCAACAGGCAGTGTGTTAATGTGACTACAGCCTAATAATCAACCTCTGGCTTCTCTCAGATTTGATCTTGGAGATCCTTCT 1621 TTCAGAAGGTCTGGCTTCCCTGTAGTCCAAAGAGACCCATCTGCCTGCATCCTACTAGTAGATCACTCTTAGCTTTCATATGGAATCTAA 1711 ATTCTGCAATGTTTCTTCTCCATATTTAATCTGTTTACCTTTTGCTGTAATCAAACCTTTTCCCCGCCACAAAGCTCCATGGCCATGTAC 1801 AACACCAATGGCTTATTTGCTGTCAAGAAAAAAAAATGGCCATTTTACCGTTTGCCAAAGCACATTTAATGCAACAAGTGCTGCCTTTTG 1891 AGCTGGTGTATTCGAATTGAATGCTTCCTCTCCCAAAATTTCATGCTGGCTTTCCAAGATGTAGCTGCTTCCCTTAATAAACTAACTATT 1981 CTCATTAAAAAAAAAAAAAAAAA

Figure 2 cDNA and deduced amino acid sequences of insularinase A.

The arrow indicates the region where the primer Insularin_3R was designed. The deduced sequence of insularinase A is shaded. Boxes indicate the amino acid sequences obtained by Edman degradation after insularinase A digestion with Lys- $\mathrm{C}$ endoproteinase. PKMCGVT, HEXXHXXGXXH and CIM sequences, Ser405 and the RGD motif are indicated in bold.

\section{Molecular mass and glycosylation analysis}

Analysis by SDS-PAGE revealed that insularinase $A$ is a non-glycosylated protein (data not shown) composed of one single chain with molecular mass of 23000 and 27000 Da under non-reducing and reducing conditions, respectively (Figure 1D, inset). When analysed by MALDITOF MS, the molecular mass of the purified protein was $22639 \mathrm{Da}$, similar to the value found by SDS-PAGE under non-reducing conditions.

\section{Partial sequencing}

Direct sequencing of native insularinase $A$ was unsuccessful, probably due to $\mathrm{N}$-terminal blockage, a common characteristic of snake venom metalloproteases (GomisRüth et al., 1994). To obtain partial internal sequence information, reduced and alkylated insularinase $A$ was digested with Lys-C endoproteinase and 10 major peptides were isolated by RP-HPLC. Five peptides were submitted to Edman degradation and the sequences obtained were CSQNQYQTYLTDHNP, NLRVAVTMA-
HELGH, FSPRYIELAVVADHGMFT, GLSFEFSK and SCIMASTIS.

\section{Cloning of the cDNA}

The sequence of the first peptide obtained (CSQNQYQTYLTDHNP) was used to screen a set of clusters of ESTs from $B$. insularis venom glands (Junqueira-de-Azevedo and Ho, 2002). Among the 33 different metalloprotease sequences described on this database, only one (BITM08A) presented a segment of total identity with this peptide. This fragment corresponded to the C-terminal region of the metalloprotease domain of a P-II precursor, which also codes for an RGD disintegrin (Figure 2). Since this cluster corresponded to a partial sequence, a primer was designed based on this EST and used to amplify the remaining $5^{\prime}$ segment of the molecule from the pooled library. The amplified fragment was cloned, completely sequenced and perfectly assembled with the original fragment, deriving the complete insularinase A cDNA sequence shown in Figure 2. All other peptide sequences obtained by Edman sequencing, totalling 64 amino acid residues, matched the translated cDNA sequence as 


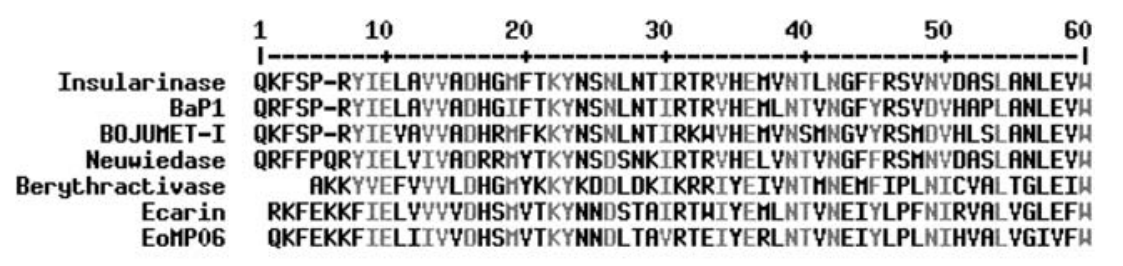

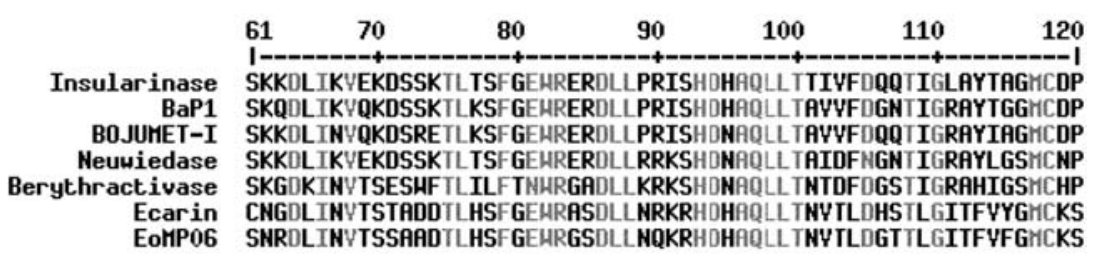

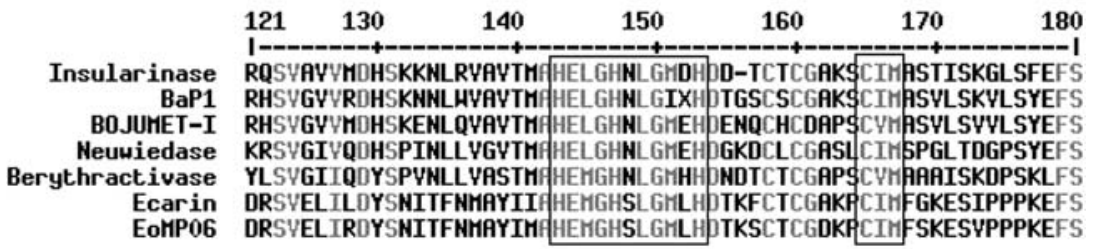

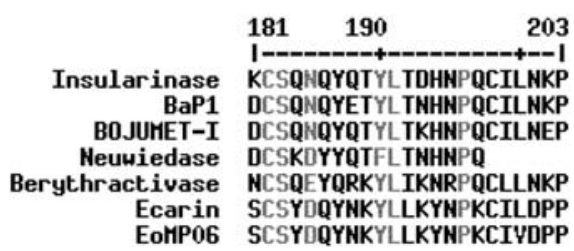

Figure 3 Comparison of the deduced amino acid sequence.

Insularinase A sequence was aligned with other members of the metalloprotease family. BaP1 (Watanabe et al., 2003), BOJUMET-I (Kashima et al., 2004) and neuwiedase (Rodrigues et al., 2000) are fibrin(ogen)olytic P-I SVMPs. Berythractivase (Silva et al., 2003), ecarin (Nishida et al., 1995) and EoMP06 (Hasson et al., 2003) are prothrombin activators P-III SVMPs. Residues in grey indicate high consensus. Boxes indicate the putative zinc ligands and active site.

shown in Figure 2, confirming that this was indeed the cDNA precursor of insularinase $A$.

The isolated cDNA clone consists of $1986 \mathrm{bp}$ and presents a signal peptide, an N-terminal pro-domain containing the highly conserved PKMCGVT segment, a central protease domain with HEXXHXXGXXH and CIM sequences and a C-terminal disintegrin possessing the RGD triad, coding for a typical P-II metalloprotease (Figure 2).

Similar to other PII metatolloproteases, the insularinase A precursor has a serine residue at position 405 (Figure 2 ), indicating that this pre-pro-metalloprotease is further processed, resulting in mature insularinase $A$ and disintegrin. Located between the protease and the disintegrin domains, residue Ser405 is highly conserved in the processed enzymes. On other hand, this residue is replaced by Cys405 in all members of the known metalloprotease/ disintegrin/cysteine-rich proteins that are not further processed in metalloprotease and disintegrin domains (Selistre et al., 1997).

Mature insularinase $A$ is composed of 203 amino acid residues, including six cysteine residues (Figure 3 ), which is in accordance with the molecular masses determined either by MALDI-TOF (22 $639 \mathrm{Da}$ ) or by SDS-PAGE under non-reducing conditions $(23 \mathrm{kDa})$. Based on its amino acid sequence, an isoelectric point of 7.8 was calculated. Potential sites for $\mathrm{N}$-glycosylation have not been identified in the insularinase $A$ sequence.
When compared with other SVMPs, its sequence presented high similarity with BaP1 (82\%), a haemorrhagic and fibrin(ogen)olytic P-I metalloprotease from Bothrops asper venom (Watanabe et al., 2003), with BOJUMET-I (78\%), a P-I metalloproteases from Bothrops jararacussu venom (Kashima et al., 2004), and with neuwiedase (70\%), a non-haemorrhagic and fibrin(ogen)olytic P-I metalloprotease from Bothrops neuwiedi venom (Rodrigues et al., 2000). On the other hand, the similarity between insularinase $A$ and prothrombin activators was lower: $52 \%$ with berythractivase from Bothrops erythromelas (Silva et al., 2003), 48\% with ecarin precursor from Echis carinatus venom (Nishida et al., 1995) and $46 \%$ with EoMP06 isolated from Echis ocellatus venom (Hasson et al., 2003), all of them P-III metalloproteases corresponding to group $\mathrm{A}$ prothrombin activators.

\section{Prothrombin activation}

Prothrombin was rapidly activated by insularinase $A$ in a dose-dependent manner (Figure 4A), independently of the presence of phospholipids and similarly under conditions with or without exogenous $\mathrm{Ca}^{2+}$ (data not shown). The prothrombin activation by insularinase $A$ was completely abolished by the metal chelator EDTA (10 mM) and by the metalloprotease inhibitor 1,10-phenanthroline (10 $\mathrm{mm})$, but not by the serine protease inhibitor phenylmethylsulfonyl fluoride (PMSF) (5 mM) (Figure 4A). The 

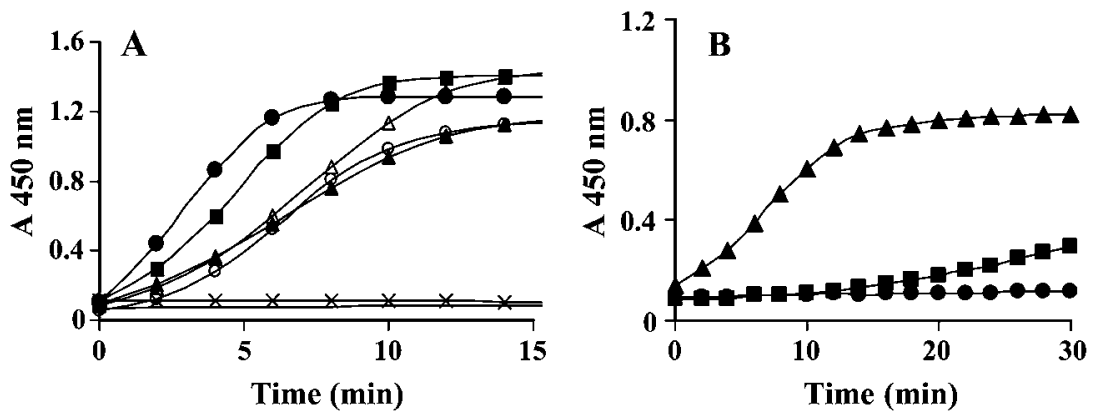

Figure 4 Prothrombin activation.

(A) Incubation of 4.5-36 nм insularinase A $(0.01-0.08 \mu \mathrm{g})$ pre-incubated or not with inhibitors with $90 \mathrm{~nm}$ prothrombin and chromogenic substrate S-2238 $(500 \mu \mathrm{M})$ in $0.05 \mathrm{M}$ Tris- $\mathrm{HCl}, \mathrm{pH} 7.4$ to a final volume of $100 \mu \mathrm{l}$, at $37^{\circ} \mathrm{C}$ for $15 \mathrm{~min}:(\mathbf{\Delta}) 4.5 \mathrm{nM},(\Delta) 9 \mathrm{nM}$, (ロ) $18 \mathrm{~nm}$ and $(\bullet) 36 \mathrm{~nm}$ insularinase $\mathrm{A}$; $(\bigcirc) 4.5 \mathrm{~nm}$ insularinase A+PMSF $(5 \mathrm{~mm}) ;(\times) 4.5 \mathrm{~nm}$ insularinase A+EDTA (10 mM) and $4.5 \mathrm{~nm}$ insularinase $A+1,10$-phenanthroline $(10 \mathrm{~mm})$. Final concentrations of PMSF, EDTA and 1,10-phenanthroline in the final reaction volume $(100 \mu \mathrm{l})$ were $0.05,0.10$ and $0.10 \mathrm{~mm}$, respectively. (B) Incubation of $4.5 \mathrm{~nm}$ factor Xa with $90 \mathrm{~nm}$ prothrombin and $500 \mu \mathrm{M}$ S-2238 in $0.05 \mathrm{M}$ Tris- $\mathrm{HCl}, \mathrm{pH} 7.4$, at $37^{\circ} \mathrm{C}$ for $30 \mathrm{~min}$, in the presence $(\mathbf{\Delta})$ or absence (ם) of the prothrombinase components. - (A) and (B): prothrombin $+S-2238$. Values correspond to final concentrations.

catalytic efficiency of insularinase A (4.5 nM) was comparable to factor Xa ( $4.5 \mathrm{~nm})$ in the prothrombinase complex (Figure 4B). Insularinase $A$ and factor Xa were not able to directly hydrolyse S-2238 (data not shown).

\section{Analysis of prothrombin fragments}

The activation of prothrombin by insularinase $A$ is shown in Figure 5. Under reducing conditions, the main hydrolysis products presented molecular masses of 55 and $32 \mathrm{kDa}$ (Figure 5A), probably corresponding to a F1/F2/A fragment and the thrombin $B$-chain, respectively, which points to the generation of meizothrombin. Under nonreducing conditions, beyond the $36-\mathrm{kDa}$ band, corresponding to the thrombin A-B chain, a fragment of $52 \mathrm{kDa}$ was detected (Figure 5B), apparently corresponding to the F1/F2 fragment resulting from the autocatalytic action of meizothrombin generated.

\section{Activity on human plasma}

Insularinase A clotted human citrated plasma with an MCD value (defined as the concentration of protein inducing plasma coagulation in $60 \mathrm{~s}$ ) of $0.3 \mu \mathrm{M}$.

\section{Factor $\mathrm{X}$ activation}

Insularinase $A$ was less effective in activating factor $X$ and this activity was dependent on pre-incubation of higher concentrations of the purified protein with factor $X$ (Figure $6 A$ ). The activation of factor $X$ by insularinase A was completely abolished by EDTA (10 mM) or 1,10phenanthroline (10 mM) (Figure 6B). This metalloprotease was not able to directly hydrolyse the chromogenic substrate S-2765 (data not shown).

\section{Fibrinolytic and fibrinogenolytic activities}

Insularinase A has lower fibrinolytic and fibrinogenolytic activities when compared to prothrombin activation. Lysis areas on fibrin plates and the degradation of fibrinogen were obtained with higher concentrations of the enzyme and after a longer incubation period.
The purified protein $(20 \mu \mathrm{g})$ induced a lysis area of $480 \mathrm{~mm}^{2}$ after 18-h incubation. The lysis was completely inhibited by 1,10-phenanthroline, while no inhibition was observed even when high concentrations of PMSF $(10 \mathrm{~mm})$ were used. The protein did not clot fibrinogen, indicating that it is devoid of thrombin-like activity. The fibrinogenolytic activity of insularinase $A$ was directed toward the $A \alpha$ - and $B \beta$-chains of the fibrinogen molecule, without affecting the $\gamma$-chains. The A $\alpha$-chain was

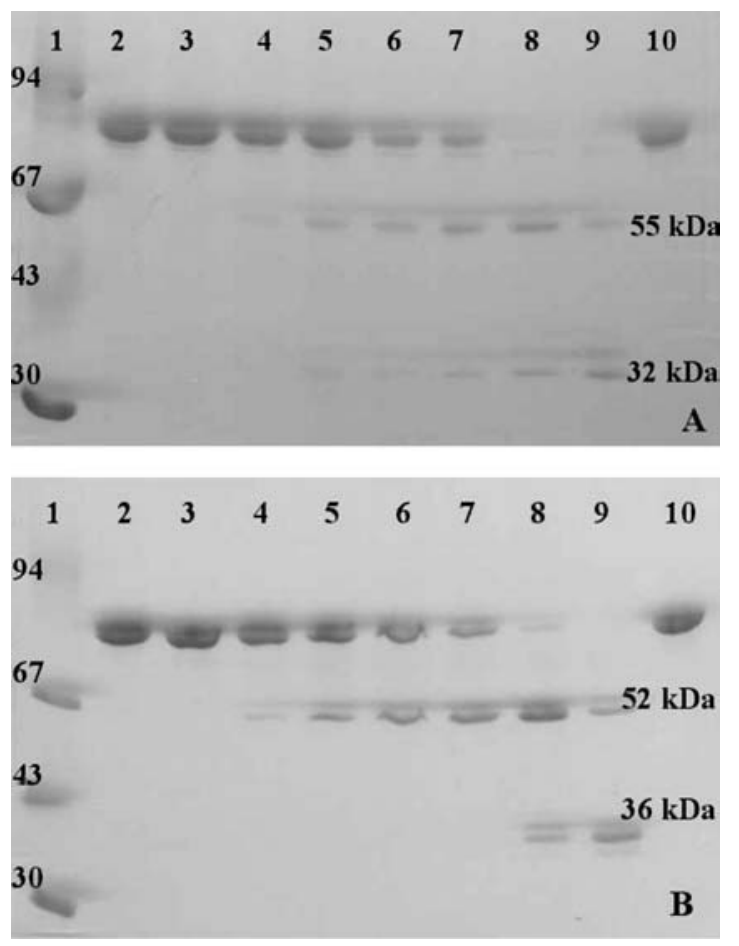

Figure 5 Hydrolysis of prothrombin by insularinase A.

SDS-PAGE (10\%) of prothrombin after incubation at $37^{\circ} \mathrm{C}$ with insularinase $A$ for $0,5,10,15,20,30$ and 60 min (lanes 3-9, respectively) at a protease/prothrombin molar ratio of 1:20, under reducing (A) and non-reducing (B) conditions. Lane 1, molecular-mass markers (phosphorylase b, $94 \mathrm{kDa}$; albumin, $67 \mathrm{kDa}$; ovoalbumin, $43 \mathrm{kDa}$; carbonic anhydrase, $30 \mathrm{kDa}$ ). Lanes 2 and 10, prothrombin incubated for 0 and $24 \mathrm{~h}$, respectively. 

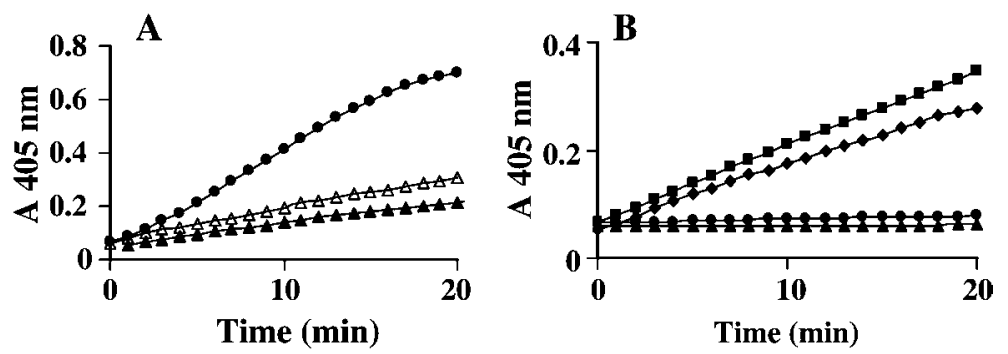

Figure 6 Factor $X$ activation by insularinase $A$.

(A) Incubation of 0.3-2.25 $\mu \mathrm{M}$ insularinase $A(0.675-5.0 \mu \mathrm{g})$, preincubated with $0.7 \mu \mathrm{M}$ factor $X$ for $15 \mathrm{~min}$, with chromogenic substrate

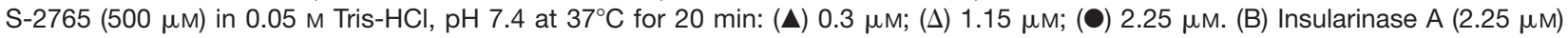
was pre-incubated with $10 \mathrm{mM}$ EDTA, $10 \mathrm{mM}$ 1,10-phenanthroline or $5 \mathrm{mM} \mathrm{PMSF}$ at $37^{\circ} \mathrm{C}$ for $30 \mathrm{~min}$. Mixtures of protein/inhibitor were incubated with prothrombin and substrates as described above. Final concentrations of PMSF, EDTA and 1,10-phenanthroline in the reaction were $0.05,0.10$ and $0.10 \mathrm{~mm}$, respectively: $(\boldsymbol{\square}) 2.25 \mu \mathrm{M}$ insularinase $\mathrm{A}$; $(\bullet)$ insularinase A+PMSF; (๑) insularinase A+EDTA; $(\mathbf{\Lambda})$ insularinase $A+1,10-$ phenanthroline. Values correspond to final concentrations.

completely digested after $30 \mathrm{~min}$, while the $\mathrm{B} \beta$-chain was fully degraded after $2 \mathrm{~h}$ (Figure 7).

\section{HUVEC studies}

Under our assay conditions, insularinase A was not able to induce either detachment or apoptosis of human umbilical cord vein endothelial cells (HUVECs) cultured in medium supplemented with either $1 \%$ or $10 \%$ FBS. In addition, the protease neither induced cell proliferation nor promoted an increase in the endothelial cell growth factor (ECGF) effect. After analysing cell adhesion molecules by flow cytometry, we demonstrated that insularinase $A$ did not increase the expression levels of E-selectin, ICAM-1 or DAF. On the other hand, insularinase A significantly increased the liberation of $\mathrm{NO}$ and $\mathrm{PGI}_{2}$ by HUVECs, but not of t-PA. The effect of $0.22 \mu \mathrm{M}$ insularinase $A$ on nitric oxide release was similar to effect

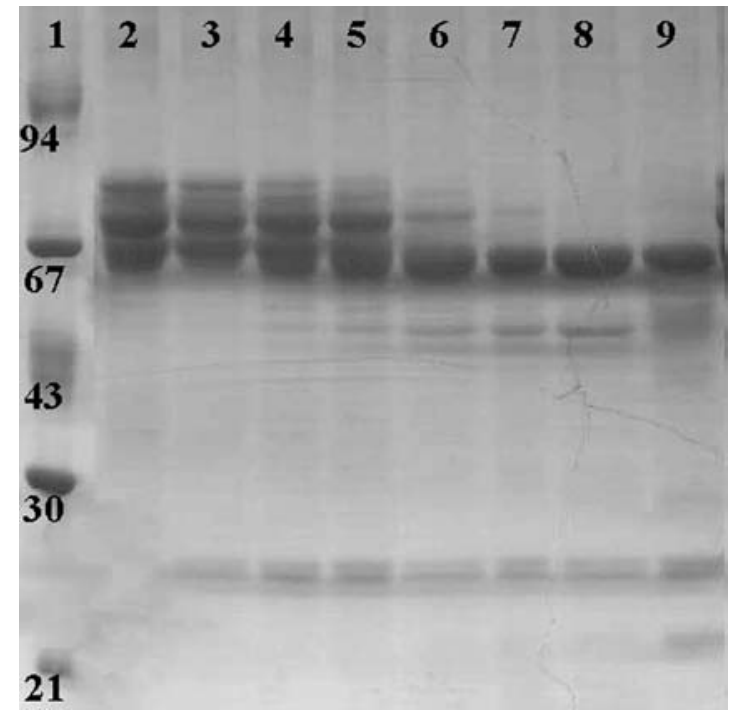

Figure 7 Bovine fibrinogen degradation by insularinase $A$. SDS-PAGE $(10 \%)$ of fibrinogen after incubation at $37^{\circ} \mathrm{C}$ with insularinase A for $0,5,10,30,60,120$ min and $24 \mathrm{~h}$ (lanes 3-9, respectively) at a protease/fibrinogen molar ratio of 1:6.5, under reducing conditions. Lane 1, molecular mass markers (phosphorylase $b, 94 \mathrm{kDa}$; albumin, $67 \mathrm{kDa}$; ovoalbumin, $43 \mathrm{kDa}$; carbonic anhydrase, $30 \mathrm{kDa}$; trypsin inhibitor, $21 \mathrm{kDa}$ ). Lane 2, fibrinogen incubated for $24 \mathrm{~h}$. of thrombin and did not increase further when higher concentrations of insularinase were used (Figure 8). Contrary to nitric oxide, after $1 \mathrm{~h}$ of incubation with insularinase $(0.22 \mu \mathrm{M})$ the concentrations of 6-ketoprostaglandin $\mathrm{F} 1 \alpha$ on HUVEC supernatants were only weakly increased compared to thrombin (Figure 9). 6Keto-prostaglandin $\mathrm{F} 1 \alpha$ levels on $24 \mathrm{~h}$ supernatants revealed significantly increased $\mathrm{PGI}_{2}$ levels only for thrombin-pretreated HUVECs (data not shown).

\section{Hemorrhagic activity}

In contrast with $B$. insularis venom $(10 \mu \mathrm{g})$, insularinase A $(10-100 \mu \mathrm{g})$ did not show hemorrhagic activity when injected into the dorsal skin of mice (data not shown).

\section{Discussion}

Prothrombin-activating metalloproteases already purified from snake venoms are single- or double-chain proteases with high molecular masses, belonging to class

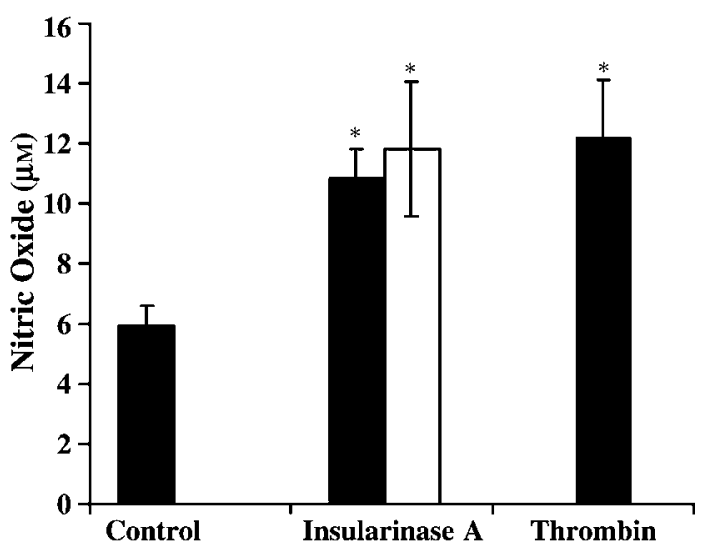

Figure 8 Effect of insularinase $A$ on nitric oxide release by HUVECs.

HUVECs treated with 0.22 or $1 \mu \mathrm{M}$ insularinase A (5 or 23 $\mu \mathrm{g} / \mathrm{ml})$ for $1 \mathrm{~h}$ at $37^{\circ} \mathrm{C}$. Nitrite and nitrate in the supernatants were reduced with a $\mathrm{VCl}_{3}$-saturated solution in $1 \mathrm{M} \mathrm{HCl}$ at $90^{\circ} \mathrm{C}$, and the nitric oxide generated was measured by NO-ozone chemiluminescence in the gaseous phase. Results are the mean values \pm SEM of four independent experiments, performed in triplicate. $p<0.005$ by Student's $t$-test. 


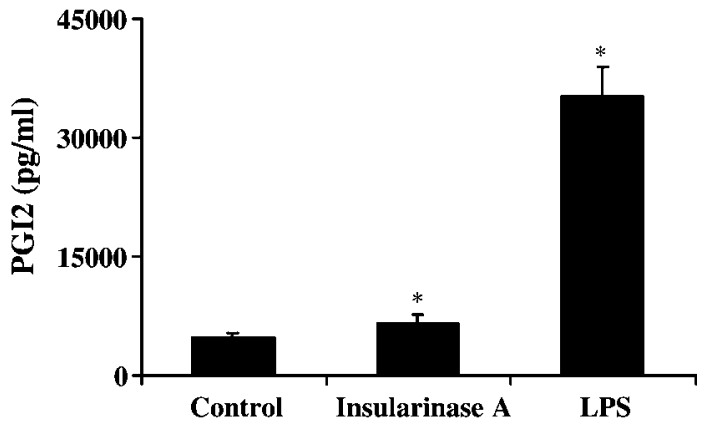

Figure 9 Effect of insularinase A on prostacyclin production by HUVECs.

HUVECs were treated with $0.22 \mu \mathrm{M}$ insularinase $\mathrm{A}(5 \mu \mathrm{g} / \mathrm{ml})$ or $5 \mathrm{U} / \mathrm{ml}$ thrombin for $1 \mathrm{~h}$ at $37^{\circ} \mathrm{C}$. 6-Keto-prostaglandin $\mathrm{F} 1 \alpha$ levels were measured in culture supernatants using commercial ELISA kits. Results are the mean values \pm SEM of four independent experiments, performed in triplicate. $p<0.005$ by Student's $t$ test.

P-III (Govers-Riemslag et al., 1987; Hofmann and Bon, 1987; Loria et al., 2003; Silva et al., 2003) or class P-IV (Yamada et al., 1996; Gao et al., 2002). In the present study, we have described the first low-molecular-mass metalloprotease with prothrombin activating activity, named insularinase $A$. The enzyme was isolated from Bothrops insularis venom as a non-glycosylated singlechain protein of approximately $22600 \mathrm{Da}$, classified as a P-I metalloprotease (Bjarnason and Fox, 1995). Insularinase $\mathrm{A}$ activates prothrombin in a $\mathrm{Ca}^{+2}$-independent manner, generating meizothrombin as an intermediate product. Thus, this enzyme resembles other class A prothrombin activators, such as ecarin from the venom of $E$. carinatus (Nishida et al., 1995), basparin A from B. asper venom (Loria et al., 2003) and berythractivase from $B$. erythromelas (Silva et al., 2003).

In addition to insularinase $\mathrm{A}$, prothrombin activation by berythractivase was also tested indirectly using S-2238 substrate (Silva et al., 2003). However, in contrast to insularinase A, a higher dose of berythractivase $(60 \mathrm{~mm})$ and a lower concentration of prothrombin (44 nM) were used, suggesting that this P-III class metalloprotease is less powerful in activating prothrombin compared to insularinase A. Similarly, the serine protease lopap, isolated from bristle extracts of the caterpillar Lonomia obliqua (Reis et al., 2001), also showed lower activity in activating prothrombin compared to insularinase $A$.

Interestingly, prothrombin activation by insularinase $A$ was higher than that of factor $\mathrm{Xa}$ alone and comparable to activation by factor $\mathrm{Xa}$ in the prothrombinase complex. Factor $\mathrm{Xa}$ is a vitamin $\mathrm{K}$-dependent serine protease that forms a high-affinity complex with other components of the prothrombinase complex (factor $\mathrm{Va}$, negatively charged phospholipid vesicles and calcium) to activate prothrombin to thrombin during the blood coagulation process. These results demonstrate the high catalytic efficiency of insularinase A.

At higher concentrations and for longer incubation times, insularinase A was also capable of degrading fibrinogen and fibrin. Despite its fibrin(ogen)olytic activity, insularinase $A$ produced rapid and consistent human plasma clots, indicating that this metalloprotease is pref- erentially a procoagulant molecule. The clots formed were stable for hours, indicating that its fibrinogenolytic activity is less efficient in the presence of cross-linked fibrin. Corroborating these data, fibrin lysis areas (on fibrin plates) were only observed after $18 \mathrm{~h}$ incubation. Since insularinase $A$ does not show thrombin-like activity and is only able to activate factor $X$ at high concentrations, its clotting activity is probably the result of its capacity to activate prothrombin. Insularinase A was fully inhibited by 1,10-phenanthroline, indicating that the various biological properties of this enzyme are dependent on its catalytic activity.

Recently, a potent procoagulant P-III metalloprotease isolated from a bothropic venom was described by Loria et al. (2003). Basparin A, isolated from Bothrops asper venom, is also a group A prothrombin activator; however, it exhibits higher clotting potential on human plasma compared to insularinase A. As for other class P-III snake venom metalloproteases (Kamiguti et al., 1994; EstevaoCosta et al., 2000; Escalante et al., 2003), the clotting activity of basparin $A$ is not inhibited by $\alpha_{2}$-macroglobulin (Loria et al., 2003), and this may be associated with the presence of additional domains in the structure of these enzymes, which might hamper interaction with the inhibitor (Kamiguti et al., 1994). In contrast, class P-I metalloproteases are strongly inhibited by $\alpha_{2}$-macroglobulin (Souza et al., 2001; Escalante et al., 2004; Tseng et al., 2004), thus explaining the high minimum coagulant dose obtained for insularinase $A$.

Mature insularinase $A$ is found in venom as a $P-I$ metalloprotease. However, the analysis of its CDNA sequence showed that, in addition to pro- and protease domains, insularinase A precursor has a disintegrin domain containing the Arg-Gly-Asp (RGD) sequence, which is a typical signature of P-II metalloprotease precursors. It is well known that class P-I metalloproteases and disintegrins are derived from common precursors that are post-translationally processed (Kini, 1995). Similarly to insularinase $\mathrm{A}$, the disintegrin domains present in the precursors of atrolysin E and HR2a are lacking in the mature forms of these proteases (Shimokawa et al., 1997; Yamada et al., 1999). Studies using a recombinant pro-atrolysin E suggest that metalloproteases from $C$. atrox venom, including atrolysin $A$ and active atrolysin $E$, but not pro-atrolysin $E$ itself, can activate and process this precursor. The scheme of activation shows that the first cleavage by metalloproteases removes the pro-domain, followed by processing of the disintegrin domain (Shimokawa et al., 1997). Residue Ser405, located between the protease and the disintegrin domains, is highly conserved in the proteolytically processed metalloproteases (class P-II) and is replaced by Cys405 in proteins in which the disintegrin domains are not further processed (Selistre et al., 1997). Indeed, the only two class P-II metalloproteases already isolated from snake venom, jerdonitin and bilitoxin-1 from Trimeresurus jerdonii and Agkistrodon bilineatus venoms, respectively, have an additional cysteine residue (Nikai et al., 2000; Chen et al., 2003). Cys405 is known to form an intrachain disulfide bond with another cysteine residue located in the disintegrin domain, thereby avoiding separation of the metalloprotease and the disintegrin domains (Siigur et al., 1996). The insularinase 
A precursor, as well as all other processed P-Il metalloproteases, has a serine residue in the 405 position.

Analysis of the deduced amino acid sequence of insularinase A showed only moderate similarity to prothrombin activators. Despite this, the fragments generated after prothrombin activation by berythractivase, ecarin and EoMP06 are similar to those formed by insularinase A (Nishida et al., 1995; Hasson et al., 2003; Silva et al., 2003).

Different to classical prothrombin activators, insularinase A exhibits high similarity with several haemorrhagic and non-haemorrhagic fibrin(ogen)olytic metalloproteases. The highest homology was found with BaP1 from Bothrops asper venom (82\% identity). Despite this high sequence identity, insularinase $\mathrm{A}$ and BaP1 exhibit distinct effects on blood coagulation and on endothelial cells. BaP1 is a fibrinogenolytic P-I metalloprotease with weak haemorrhagic activity and devoid of procoagulant activity. In addition, BaP1 induces detachment of endothelial cells by proteolysis of the matrix components, resulting in anoikis independent of the $\mathrm{Bcl}-2$ family members $\mathrm{Bax}$ and $\mathrm{Bcl}-\mathrm{xL}$ and associated with caspase- 8 activation and CFLIP $P_{\mathrm{L}}$ up-regulation (Gutierrez et al., 1995; Rucavado et al., 1995; Diaz et al., 2005). Anoikis is a subtype of apoptosis induced by disruption of cell-matrix interactions. Cell-cell and cell-matrix contacts are necessary for the maintenance of anchorage-dependent cell survival (Mallat and Tedgui, 2000). In contrast to BaP1, insularinase $A$ is preferentially procoagulant and is not able to induce either detachment or apoptosis of endothelial cells.

In general, cell adhesion molecules are known to help recruitment, adhesion and transendothelial migration of leukocytes into tissues (Smith et al., 1989; Springer, 1994; van de Stolpe and van der Saag, 1996). Insularinase $A$ did not increase surface expression of ICAM-1, E-selectin or DAF, molecules playing an important role in inflammatory responses.

In vivo, a powerful triad composed of prostacyclin $\left(\mathrm{PGI}_{2}\right)$, nitric oxide (NO) and tissue plasminogen activator (t-PA) is secreted by endothelial cells, regulating thrombo-resistance and vascular tone. Alliance between them occurs at the level of protection against the deposition of thrombi over the vascular wall. Activation of fibrinolysis by t-PA through the generation of plasmin is complemented with the inhibition of platelet aggregation by $\mathrm{PGI}_{2}$ and by inhibition of the release of plasminogen activator inhibitor-1 (PAl-1) from platelets by NO. On the other hand, endothelial regulation of vascular tone is exclusively NO-dependent (Gryglewski, 1995).

Our studies demonstrated that insularinase A significantly increases the NO released by endothelial cells similarly to thrombin. Since NO is a relevant regulator of the vascular tone, it is possible to suggest its involvement in the hypotension state occurring in severe human envenomations by Bothrops snake venoms (Rosenfeld, 1971).

On the other hand, t-PA release was not modified by insularinase $A$ and only a slight increase in $\mathrm{PGI}_{2}$ release by endothelial cells was observed. Taking into account that $P G I_{2}$ is a potent platelet activation inhibitor, its increased release could be involved with the inhibition of aggregation in vivo.
The ability of SVMPs to induce haemorrhage has been associated with their capacity to hydrolyse extracellular matrix (ECM) proteins (Bjarnason and Fox, 1994; Hati et al., 1999) and large variations in the haemorrhagic potency of SVMPs are observed. Phylogenetic analyses based on 30 complete sequences of P-I metalloproteases revealed that they may be classified into three functional subtypes: highly haemorrhagic acidic enzymes, moderately haemorrhagic basic enzymes, and non-haemorrhagic neutral enzymes (Tsai et al., 2000). In agreement with this classification, insularinase $A$, with a neutral pl, was devoid of haemorrhagic activity when tested in the dorsal skin of mice. It's important to mention that the haemorrhagic activity of insularinase A could not be assayed by intravital microscopy because, as a result of its high procoagulant activity, thrombus formation was observed in small vessels even when using low doses of the protease (data not shown).

In summary, we have isolated and characterised insularinase $\mathrm{A}$ and cloned the respective gene of the first prothrombin activator belonging to the $\mathrm{P}-\mathrm{I}$ metalloprotease class. Despite the moderate similarity to ecarin and berythractivase, insularinase $A$ is a classic group A prothrombin activator. Moreover, insularinase $A$ also shows other secondary activities, all of which are dependent on its catalytic activity. However, structural elements involved in modulating the interaction of insularinase $A$ with its substrates remain unknown.

\section{Materials and methods}

\section{Reagents}

Bothrops insularis crude venom was obtained from Butantan Institute, SP, Brazil. Benzamidine Sepharose 6B, Resource-S and Superdex 200 columns and dithiothreitol (DTT) were from Amersham Biosciences (Uppsala, Sweden). 1,10-Phenanthroline monohydrate was purchased from Merck (Darmstadt, Germany) and PMSF from Acros Organics (Morris Plains, NJ, USA). Chromogenic substrates H-D-Phe-PIP-Arg-pNA (S-2238) and $N-\alpha-Z-$ D-Arg-Gly-Arg-pNA (S-2765) were from Chromogenix (Milan, Italy). EDTA, L-glutamine, 2-mercaptoethanol, human factor II, human factor $\mathrm{X}$, factor $\mathrm{Xa}$, factor $\mathrm{Va}$, bovine fibrinogen $(90 \%$ clottable), human thrombin, endothelial cell growth factor (ECGF) and iodoacetamide were purchased from Sigma Chemical Co. (St. Louis, MO, USA). Monoclonal antibodies PE-conjugatedanti-CD54, CD55 and CD62E were obtained from PharMingen (BD Biosciences, San Diego, CA, USA). Endothelial cell growth supplement from bovine neural tissue was purchased from Calbiochem (La Jolla, CA, USA). Foetal bovine serum (FBS), trypsin, RPMI 1640 medium, HAM F 12 medium, penicillin and streptomycin were purchased from Cultilab (Campinas, SP, Brazil). EIA kit 6-keto-prostaglandin F1 $\alpha$ was obtained from Cayman Chemical Company (Ann Arbor, MI, USA) and the T-PA ELISA kit was purchased from Oncogene Research Products (San Diego, CA, USA). Sequencing grade endoproteinase Lys-C was from Boehringer Mannheim (Mannheim, Germany). All other chemicals used were of the highest purity commercially available.

\section{Purification of insularinase A}

Chromatography assays were performed using the FPLC system from Amersham Biosciences. Lyophilised crude venom samples dissolved in $2 \mathrm{ml}$ of $0.02 \mathrm{M}$ sodium phosphate buffer, $\mathrm{pH} 7.8$ were fractionated on a benzamidine Sepharose 6B affin- 
ity column, pre-equilibrated with the same buffer at a flow rate of $2 \mathrm{ml} / \mathrm{min}$. Proteins were eluted in three steps using $0.02 \mathrm{M}$ phosphate buffer, $\mathrm{pH} 7.8$, and the same buffer containing $0.5 \mathrm{M}$ $\mathrm{NaCl}$ and $0.02 \mathrm{M}$ glycine buffer, $\mathrm{pH}$ 3.2. The fraction unbound to the column was concentrated, dialysed against $0.05 \mathrm{M} 2-(\mathrm{N}-$ morpholino)ethane sulfonic acid (MES) buffer, pH 6.0, and subsequently submitted to a Resource $S$ column equilibrated with the same buffer. Elution was carried out isocratically with the equilibration buffer, followed by a linear $\mathrm{NaCl}$ gradient from 0 to $1 \mathrm{M}$ in the same buffer at a flow rate of $3 \mathrm{ml} / \mathrm{min}$. Eluted fractions were tested for their ability to activate prothrombin and the more active pool was submitted to a Superdex 200 column, previously equilibrated with $0.05 \mathrm{M}$ Tris- $\mathrm{HCl}$ buffer, $\mathrm{pH} 8.0$, at a flow rate of $0.5 \mathrm{ml} / \mathrm{min}$. Finally, the purified active protein was chromatographed on an RP-HPLC $\mathrm{C}_{8}$ column (Beckman, Fullerton, CA, USA) at a flow rate of $1 \mathrm{ml} / \mathrm{min}$. Elution was performed with an increasing gradient from $0 \%$ solvent $\mathrm{A}[0.1 \%$ trifluoroacetic acid (TFA) in water] to $80 \%$ solvent $\mathrm{B}$ ( $0.1 \%$ TFA in $90 \%$ acetonitrile). Protein contents were determined either by the method of Markwell et al. (1978) or by measuring the absorbance at $280 \mathrm{~nm}$.

\section{Molecular mass and glycosylation analysis}

The insularinase A molecular mass was determined by matrixassisted laser desorption/ionisation-time-of-flight mass spectrometry (MALDI-TOF MS) on a Voyager DE-PRO instrument (Perseptive Biosystems, Framingham, MA, USA). The matrix used was 3,5-dimethoxy-4-hydroxycinnamic acid. Insularinase A under reducing and no- reducing conditions was also analysed by sodium dodecyl sulfate-polyacrylamide gel electrophoresis (SDS-PAGE) in $12 \%$ separating and $4 \%$ stacking gels (Laemmli, 1970). Gels were stained with Coomassie brilliant blue R250 for mass molecular analysis and with periodic acid-Schiff (PAS) stain according to Segrest and Jackson (1972) for detection of glycosylation.

\section{Amino acid sequence}

Native insularinase $(10 \mu \mathrm{g})$ was desalted through a ProSorb cartridge (Perkin Elmer, Foster City, CA, USA) and directly submitted to $\mathrm{N}$-terminal sequencing. Another aliquot of insularinase $\mathrm{A}$ $(100 \mu \mathrm{g})$ was dissolved in $40 \mu \mathrm{l}$ of $0.5 \mathrm{M}$ Tris-HCl buffer, $\mathrm{pH}$ 8.3, containing $6 \mathrm{M}$ guanidine $\mathrm{HCl}$ and $1 \mathrm{mM}$ EDTA, and incubated for $30 \mathrm{~min}$ at $50^{\circ} \mathrm{C}$. A 20 -fold molar excess of DTT, assuming seven cysteine residues in insularinase $A$, was added to the reaction mixture for $1 \mathrm{~h}$ at $50^{\circ} \mathrm{C}$. This assumption was based on the Cys contents of the two metalloproteases from Bothrops insularis venom for which the cDNAs were completely sequenced (Junqueira-de-Azevedo and Ho, 2002). Alkylation of free thiol groups was performed after incubation with a 1.5-fold molar excess of iodoacetamide for $1 \mathrm{~h}$ at room temperature in the dark. All incubations were performed under nitrogen. Excess reagents were removed by RP-HPLC on a Vydac $\mathrm{C}_{18}$ column (The Separations Group, Hesperia, CA, USA) using a flow rate of $0.2 \mathrm{ml} / \mathrm{min}$. The absorbance was monitored at $215 \mathrm{~nm}$. The solvent system used was $0.1 \%$ TFA in water (solvent $A$ ) and $0.09 \%$ TFA in acetonitrile (solvent B). The gradient was $5 \%$ solvent $B$ for $15 \mathrm{~min}, 75 \% \mathrm{~B}$ at $50 \mathrm{~min}$ and $75 \%$ B for $10 \mathrm{~min}$. Reduced and alkylated insularinase $A$ was collected, speed vac dried, further dissolved in $50 \mu \mathrm{l}$ of $0.025 \mathrm{M}$ Tris- $\mathrm{HCl}$ buffer, $\mathrm{pH} 8.5$ containing $1 \mathrm{~mm}$ EDTA, and digested with endoproteinase Lys-C at an enzyme/substrate molar ratio of 1:50 $(\mathrm{w} / \mathrm{w})$ at $37^{\circ} \mathrm{C}$ for $18 \mathrm{~h}$. The peptides obtained by Lys-C digestion were isolated by RP-HPLC on a $\mathrm{C}_{18}$ column as described above. The gradient program started with $5 \%$ solvent $B$ for 5 min and was increased to $45 \%$ B at $55 \mathrm{~min}$ and to $75 \%$ B at $60 \mathrm{~min}$. Peptide peaks were collected, speed vac concentrated to $20 \mu \mathrm{l}$ and
Edman sequenced on a PSQ-23A protein sequencer (Shimadzu, Kyoto, Japan), according to the manufacturer's instructions.

\section{cDNA cloning}

The sequenced peptide fragments were used to screen a database of expressed sequence tags (ESTs) from $B$. insularis venom (Junqueira-de-Azevedo and Ho, 2002). From the matched EST, a specific reverse primer, Insularin_3R (5'-ACA CTG CGC CCT TGG TCT C-3'), was designed and used together with T7 primer to amplify by PCR the full-length fragment of this metalloprotease from the same cDNA library used for EST sequencing. The fragment of the expected size was cloned in the TOPO system (Life Technologies) and completely sequenced using M13F and M13R universal primers. The nucleotide sequence of insularinase $\mathrm{A}$ has been deposited in the GenBank database under the accession number AY736107.

\section{Prothrombin activation}

Activation of prothrombin was indirectly determined using the thrombin-specific substrate S-2238. The reaction was carried out in microtitre plates containing $0.05 \mathrm{M}$ Tris- $\mathrm{HCl}$ buffer, $\mathrm{pH} 7.4$, $90 \mathrm{~nm}$ prothrombin (factor II), 4.5-36 nM insularinase $A$ $(0.01-0.08 \mu \mathrm{g})$ or $4.5 \mathrm{~nm}$ factor Xa and $500 \mu \mathrm{M}$ S-2238 in a final volume of $100 \mu \mathrm{l}$. To assays in the presence of the prothrombinase complex, $2.5 \mu \mathrm{M}$ factor $\mathrm{Va}, 300 \mu \mathrm{M}$ phospholipids and $10 \mathrm{mM} \mathrm{CaCl}$, were added to the buffer. Substrate cleavage by the thrombin generated was monitored by measuring the formation of $p$-nitroaniline for $30 \mathrm{~min}$ at $405 \mathrm{~nm}$, using a Spectra Max 190 spectrophotometer (Molecular Devices, Sunnyvale, CA, USA). Assays were also performed after preincubation of insularinase A with $10 \mathrm{~mm}$ 1,10-phenanthroline, $10 \mathrm{~mm}$ EDTA or $5 \mathrm{~mm}$ PMSF for $30 \mathrm{~min}$ at $37^{\circ} \mathrm{C}$. Values correspond to final concentrations.

\section{Analysis of prothrombin fragments}

The proteolytic activity of insularinase A upon prothrombin was tested in $0.05 \mathrm{M}$ Tris- $\mathrm{HCl}$ buffer, $\mathrm{pH} 7.4$, at a protease/prothrombin molar ratio of $1: 20$ at $37^{\circ} \mathrm{C}$. After $0,5,10,15,20,30$ and 60 min of incubation, aliquots of the mixture were removed and analysed under reducing and non-reducing conditions by $10 \%$ SDS-PAGE. Fragments were analysed after staining the gel with Coomassie brilliant blue R250.

\section{Activity on human plasma}

To test procoagulant activity, $0.1-0.5 \mu \mathrm{M}$ insularinase $\mathrm{A}$ $(0.225-1.125 \mu \mathrm{g})$ was incubated at $37^{\circ} \mathrm{C}$ with $100 \mu \mathrm{l}$ of human citrated plasma and the clotting time was measured. The minimum coagulant dose (MCD) was defined as the amount of protein that induced plasma coagulation in $60 \mathrm{~s}$.

\section{Factor $\mathrm{X}$ activation}

FX activation was carried out in a microtitre plate after preincubation at $37^{\circ} \mathrm{C}$ for $15 \mathrm{~min}$ of $\mathrm{FX}(0.7 \mu \mathrm{M})$ with $0.3-2.25 \mu \mathrm{M}$ insularinase A $(0.675-5.0 \mu \mathrm{g})$ in $100 \mu \mathrm{l}$ of $0.05 \mathrm{~mm}$ Tris- $\mathrm{HCl}$, $\mathrm{pH} 7.4$, followed by the addition of $400 \mu \mathrm{M}$ S-2765. The rate of substrate cleavage by FXa formed was monitored by measuring the formation of $p$-nitroaniline for $30 \mathrm{~min}$ at $405 \mathrm{~nm}$, using a Spectra Max 190 spectrophotometer. Assays were also performed after preincubation of insularinase A with $10 \mathrm{~mm} 1,10-$ phenanthroline, $10 \mathrm{~mm}$ EDTA or $5 \mathrm{~mm}$ PMSF for $30 \mathrm{~min}$ at $37^{\circ} \mathrm{C}$. Values correspond to final concentrations. 


\section{Fibrinolytic activity}

Fibrinolytic activity was measured by the fibrin-plate method, as described by Jespersen and Astrup (1983). Briefly, a fibrin-agarose gel was prepared by mixing human fibrinogen $(2 \mathrm{mg} / \mathrm{ml}$ of clotting protein) with a preheated solution of $2 \%$ agarose in $0.1 \mathrm{M}$ sodium barbital buffer, $\mathrm{pH} 7.75$, and $20 \mathrm{U} / \mathrm{ml}$ thrombin. Samples of $20 \mu \mathrm{g}$ insularinase $\mathrm{A}$ alone or preincubated at $37^{\circ} \mathrm{C}$ for 10 min with the protease inhibitors PMSF $(10 \mathrm{mM})$ or $1,10-$ phenanthroline $(10 \mathrm{mM})$ were applied to wells of the solidified gel and incubated at $37^{\circ} \mathrm{C}$ for $18 \mathrm{~h}$. The lysed area was then measured.

\section{Fibrinogenolytic activity}

Bovine fibrinogen solution ( $2 \mathrm{mg} / \mathrm{ml}$ clotting protein), diluted in $0.05 \mathrm{M}$ Tris- $\mathrm{HCl}$ buffer, $\mathrm{pH} 7.3$, containing $5 \mathrm{mM} \mathrm{CaCl}_{2}$ and $0.2 \mathrm{M}$ $\mathrm{NaCl}$, was preincubated at $37^{\circ} \mathrm{C}$ with insularinase $A$ at a 1:6.5 molar ratio (insularinase A/fibrinogen). Aliquots of $30 \mu \mathrm{l}$ were removed at $0,5,10,30,60,120 \mathrm{~min}$ and $24 \mathrm{~h}$ and subjected to $10 \%$ SDS-PAGE under reducing conditions. Fibrinogen fragments were analysed after staining the gel with Coomassie Brilliant Blue R250.

\section{HUVEC studies}

Cell cultures Endothelial cells were obtained from human umbilical-cord veins (HUVECs) by collagenase digestion as described by Jaffe et al. (1973) and cultured on gelatin-coated plastic dishes in RPMI 1640 medium supplemented with $1 \%$ or $10 \%$ (v/v) FBS, $45 \mu \mathrm{g} / \mathrm{ml}$ heparin, $25 \mu \mathrm{g} / \mathrm{ml}$ endothelial supplement growth factor, $1 \mathrm{~mm}$ sodium pyruvate, $2 \mathrm{mM}$ L-glutamine, $100 \mathrm{U} / \mathrm{ml}$ penicillin, $7 \mu \mathrm{g} / \mathrm{ml}$ polymyxin B, $50 \mu \mathrm{M}$ mercaptoethanol and $0.75 \%(\mathrm{v} / \mathrm{v})$ mouse brain extract. Cells were maintained at $37^{\circ} \mathrm{C}$ in a humidified $5 \% \mathrm{CO}_{2}$ incubator. For the assays, cells were trypsinised and cultivated on plastic culture plates precoated with gelatin at $4^{\circ} \mathrm{C}$ overnight.

Morphological changes and apoptosis HUVECs in a confluent monolayer were incubated with 0.22 or $2.2 \mu \mathrm{M}$ insularinase $\mathrm{A}$ ( 5 or $50 \mu \mathrm{g} / \mathrm{ml}$ ) for 24 or $48 \mathrm{~h}$ at $37^{\circ} \mathrm{C}$. After treatment, morphological changes were analysed by inverse microscopy (Leitz Diaplan, Wetzlar, Germany). Apoptosis was analysed by fluorescence microscopy after treatment of adherent and nonadherent cells with acridine orange $(50 \mu \mathrm{g} / \mathrm{ml})$ and ethidium bromide $(50 \mu \mathrm{g} / \mathrm{ml})$. The cell cycle was analysed by flow cytometry. Briefly, after $24 \mathrm{~h}$ incubation with $0.22 \mu \mathrm{M}$ insularinase A (5 $\mu \mathrm{g} / \mathrm{ml})$, cells were harvested and fixed in $70 \%$ ethanol. Before analysis by flow cytometry, cells were washed with phosphatebuffered saline (PBS), treated with $8 \mathrm{~g} / \mathrm{l}$ RNase, $1.2 \mathrm{~g} / \mathrm{l}$ spermine and stained with $50 \mathrm{mg} / \mathrm{l}$ propidium iodide for at least $30 \mathrm{~min}$. DNA content was determined by FACScan flow cytometry (Coulter, Scalibur, Mijdrecht, The Netherlands).

Expression of cell adhesion molecules After treatment of HUVECs with 5 or $50 \mu \mathrm{g} / \mathrm{ml}$ insularinase A $(0.22$ or $2.2 \mu \mathrm{M})$ or $2 \mu \mathrm{g} / \mathrm{ml}$ lipopolysaccharide (positive control) for $1 \mathrm{~h}$, medium was removed and the cells were further cultured for $4 \mathrm{~h}$ for expression of $\mathrm{E}$-selectin (CD62E) or $24 \mathrm{~h}$ for expression of intercellular adhesion molecule-1 (ICAM-1:CD54) and decay accelerating factor (DAF:CD55) in RPMI containing 10\% FBS. Cells were harvested by treatment with $0.25 \%$ trypsin/0.02\% EDTA solution, followed by centrifugation at $400 \mathrm{~g}$ for $10 \mathrm{~min}$ at $4^{\circ} \mathrm{C}$. The pellets were resuspended in $50 \mu \mathrm{l}$ of PBS/FBS (10\%) containing saturating concentrations of $\mathrm{PE}$-conjugated anti-CD62E, -CD54, -CD55, or equivalent concentrations of an isotypic control IgGl. After incubation for $40 \mathrm{~min}$ at $4^{\circ} \mathrm{C}$, cells were fixed with $1 \%$ paraformaldehyde and analysed by flow cytometry in a
FACScan cytofluorimeter (Becton Dickinson, Mountain View, CA, USA). Appropriate settings for forward and side scatter gates were used to examine 10000 cells per experiment.

Determination of nitric oxide release HUVECs were initially treated with 0.22 or $1 \mu \mathrm{M}$ insularinase A ( 5 or $23 \mu \mathrm{g} / \mathrm{ml}$ ) or 5 $\mathrm{U} / \mathrm{ml}$ thrombin (positive control) for $1 \mathrm{~h}$; supernatants were then collected and centrifuged at $400 \mathrm{~g}$ for $10 \mathrm{~min}$ at $4^{\circ} \mathrm{C}$. Nitric oxide was measured by reduction of its final products, nitrite and nitrate, with a $\mathrm{VCl}_{3}$-saturated solution in $1 \mathrm{M} \mathrm{HCl}$ at $90^{\circ} \mathrm{C}$. The nitric oxide generated was determined by NO-ozone chemiluminescence using a NOA ${ }^{\mathrm{TM}} 280 \mathrm{NO}$ analyser (Sievers, Boulder, CO, USA) and the concentration was calculated from a $\mathrm{NaNO}_{3}$ standard curve using Bag software 2.2 (Sievers).

Prostacyclin $\left(\mathrm{PGI}_{2}\right)$ and tissue-type plasminogen activator (t-PA) assays After treatment of HUVECs with $0.22 \mu \mathrm{M}$ insularinase $\mathrm{A}(5 \mu \mathrm{g} / \mathrm{ml})$ or $5 \mathrm{U} / \mathrm{ml}$ thrombin (positive control) for $1 \mathrm{~h}$, medium was removed and the cells were cultured for $24 \mathrm{~h}$ in RPMI containing 10\% FBS. Supernatants removed after 1 and $24 \mathrm{~h}$ were centrifuged for $10 \mathrm{~min}, 400 \mathrm{~g}$ at $4^{\circ} \mathrm{C}$, to exclude the interference of cellular debris. t-PA and 6-keto-prostaglandin $\mathrm{F} 1 \alpha\left(\mathrm{PGl}_{2}\right.$ stable metabolite) levels were measured using commercial ELISA kits.

\section{Haemorrhagic activity}

Hemorrhagic activity was determined by the method of Kondo et al. (1960) as modified by Gutierrez et al. (1995). Insularinase A $(10-100 \mu \mathrm{g})$ in $0.15 \mathrm{M} \mathrm{NaCl}$ was injected intradermally into the shaved dorsal skin of adult male Swiss mice (18-22 g). Control mice received $0.15 \mathrm{M} \mathrm{NaCl}$ (negative control) alone or $10 \mu \mathrm{g}$ of $B$. insularis venom (positive control) in $0.15 \mathrm{M} \mathrm{NaCl}$. After $2 \mathrm{~h}$, the animals were sacrificed, the dorsal skin was removed and the hemorrhagic lesions were measured.

\section{Statistics}

All results are expressed as the mean \pm SEM. Statistical analysis was performed using Student's $t$-test for paired data. Differences with a $p$ value $<0.005$ were considered statistically significant.

\section{Acknowledgements}

This study was supported by Brazilian grants from FAPESP, Fundação Butantan, CNPq, FAPERJ and PAPES-Fiocruz. We thank Dr. Alex Chapeaurouge (Departamento de Fisiologia e Farmacodinâmica, Instituto Oswaldo Cruz, RJ, Brazil) for the MALDITOF MS analysis, Dr. Sandra H.P. Farsky (Departmento de Análises Clinicas e Toxicológicas, Universidade de São Paulo, $\mathrm{SP}$, Brazil) for the intravital microscopy analysis, Dr. Luis R.C. Gonçalves (Laboratorio de Fisiopatologia, Instituto Butantan, SP, Brazil) for determination of the hemorrhagic activity, Dr. R.K. Arni and Mário Murakami (Departamento de Física, Universidade Estadual Paulista, SP, Brazil) for help in the purification of insularinase $\mathrm{A}$.

\section{References}

Bjarnason, J.B. and Fox, J.W. (1994). Hemorrhagic metalloproteinases from snake venoms. Pharmacol. Ther. 62, 325-372. Bjarnason, J.B. and Fox, J.W. (1995). Snake venom metalloendopeptidases: reprolysins. Methods Enzymol. 248, 345-368. 
Chen, R.Q., Jin, Y., Wu, J.B., Zhou, X.D., Lu, Q.M., Wang, W.Y., and Xiong, Y.L. (2003). A new protein structure of P-Il class snake venom metalloproteinases: it comprises metalloproteinase and disintegrin domains. Biochem. Biophys. Res. Commun. 310, 182-187.

Diaz, C., Valverde, L., Brenes, O., Rucavado, A., and Gutierrez, J.M. (2005). Characterization of events associated with apoptosis/anoikis induced by snake venom metalloproteinase BaP1 on human endothelial cells. J. Cell. Biochem. 94, 520-528.

Duarte, M.R., Puorto, G., and Franco, F.L. (1995). A biological survey of the pit viper Bothrops insularis Amaral (Serpentes, Viperidae): an endemic and threatened of shore island snake of southeastern Brazil. Stud. Neotrop. Fauna Environ. 30, $1-13$.

Escalante, T., Nunez, J., Moura da Silva, A.M., Rucavado, A., Theakston, R.D., and Gutierrez, J.M. (2003). Pulmonary hemorrhage induced by jararhagin, a metalloproteinase from Bothrops jararaca snake venom. Toxicol. Appl. Pharmacol. 193, 17-28.

Escalante, T., Rucavado, A., Kamiguti, A.S., Theakston, R.D., and Gutierrez, J.M. (2004). Bothrops asper metalloproteinase BaP1 is inhibited by $\alpha_{2}$-macroglobulin and mouse serum and does not induce systemic hemorrhage or coagulopathy. Toxicon 43, 213-217.

Estevao-Costa, M.I., Diniz, C.R., Magalhaes, A., Markland, F.S., and Sanchez, E.F. (2000). Action of metalloproteinases mutalysin I and II on several components of the hemostatic and fibrinolytic systems. Thromb. Res. 99, 363-376.

Gao, R., Kini, M.R., and Gopalakrishnakone, P. (2002). A novel prothrombin activator from the venom of Micropechis ikaheka: isolation and characterization. Arch. Biochem. Biophys. 408, 87-92.

Gomis-Rüth, F.X., Kress, L.F., Kellermann, J., Mayr, I., Lee, X., Huber, R., and Bode, W. (1994). Refined $2.0 \AA$ X-ray crystal structure of the snake venom zinc-endopeptidase adamalysin II. Primary and tertiary structure determination, refinement, molecular structure and comparison with astacin, collagenase and thermolysin. J. Mol. Biol. 239, 513-544.

Govers-Riemslag, J.W., Knapen, M.J., Tans, G., Zwaal, R.F., and Rosing, J. (1987). Structural and functional characterization of a prothrombin activator from the venom of Bothrops neuwiedi. Biochim. Biophys. Acta 916, 388-401.

Gryglewski, R.J. (1995). Endothelial nitric oxide, prostacyclin (PGI2) and tissue plasminogen activator (t-PA): alliance or neutrality? Pol. J. Pharmacol. 47, 467-472.

Gutiérrez, J.M. and Rucavado, A. (2000). Snake venom metalloproteinases: their role in the pathogenesis of local tissue damage. Biochimie 82, 841-850.

Gutierrez, J.M., Romero, M., Diaz, C., Borkow, G., and Ovadia, M. (1995) Isolation and characterization of a metalloproteinase with weak hemorrhagic activity from the venom of the snake Bothrops asper (Terciopelo). Toxicon 33, 19-29.

Hasson, S.S., Theakston, R.D., and Harrison, R.A. (2003). Cloning of a prothrombin activator-like metalloproteinase from the West African saw-scaled viper, Echis ocellatus. Toxicon 42, 629-634.

Hati, R., Mitra, P., Sarker, S., and Bhattacharyya, K.K. (1999). Snake venom hemorrhagins. Crit. Rev. Toxicol. 29, 1-19.

Hofmann, H. and Bon, C. (1987). Blood coagulation induced by the venom of Bothrops atrox. 1. Identification, purification, and properties of a prothrombin activator. Biochemistry 26, 772-780

Jaffe, E.A., Nachman, R.L., Becker, C.G., and Minick, C.R. (1973). Culture of human endothelial cells derived from umbilical veins. Identification by morphologic and immunologic criteria. J. Clin. Invest. 52, 2745-2756.

Jespersen, J. and Astrup, T. (1983) A study of the fibrin plate assay of fibrinolytic agents. Optimal conditions, reproducibility and precision. Haemostasis 13, 301-315.
Jia, L.G., Shimokawa, K., Bjarnason, J.B., and Fox, J.W. (1996). Snake venom metalloproteinases: structure, function and relationship to the ADAMs family of proteins. Toxicon 34, 1269-1276.

Junqueira-de-Azevedo, I.L. and Ho, P.L. (2002). A survey of gene expression and diversity in the venom glands of the pit viper snake Bothrops insularis through the generation of expressed sequence tags (ESTs). Gene 299, 279-291.

Kamiguti, A.S., Desmond, H.P., Theakston, R.D., Hay, C.R., and Zuzel, M. (1994). Ineffectiveness of the inhibition of the main haemorrhagic metalloproteinase from Bothrops jararaca venom by its only plasma inhibitor, $\alpha_{2}$-macroglobulin. Biochim. Biophys. Acta 1200, 307-314.

Kashima, S., Roberto, P.G., Soares, A.M., Astolfi-Filho, S., Pereira, J.O., Giuliati, S., Faria, M. Jr., Xavier, M.A., Fontes, M.R., Giglio, J.R., and Franca, S.C. (2004). Analysis of Bothrops jararacussu venomous gland transcriptome focusing on structural and functional aspects: l--gene expression profile of highly expressed phospholipases $\mathrm{A}_{2}$. Biochimie 86 , 211-219.

Kini, R.M. (1995). Do we know the complete sequence of metalloproteinase and nonenzymatic platelet aggregation inhibitor (disintegrin) precursor proteins? Toxicon 33, 1151-1160.

Kini, R.M., Rao, V.S., and Joseph, J.S. (2001). Procoagulant proteins from snake venoms. Haemostasis 31, 218-224.

Kondo, H., Kondo, S., Ikezawa, H., and Murata, R. (1960). Studies on the quantitative method for determination of hemorrhagic activity of Habu snake venom. Jpn. J. Med. Sci. Biol. 13, 43-52.

Laemmli, U.K. (1970). Cleavage of structural proteins during the assembly of the head of bacteriophage T4. Nature 227, 680-685.

Loria, G.D., Rucavado, A., Kamiguti, A.S., Theakston, R.D., Fox, J.W., Alape, A., and Gutierrez, J.M. (2003). Characterization of 'basparin A', a prothrombin-activating metalloproteinase, from the venom of the snake Bothrops asper that inhibits platelet aggregation and induces defibrination and thrombosis. Arch. Biochem. Biophys. 418, 13-24.

Mallat, Z. and Tedgui, A. (2000). Apoptosis in the vasculature: mechanisms and functional importance. Br. J. Pharmacol. 130, 947-962.

Markwell, M.A., Haas, S.M., Bieber, L.L., and Tolbert, N.E. (1978). A modification of the Lowry procedure to simplify protein determination in membrane and lipoprotein samples. Anal. Biochem. 87, 206-210.

Nikai, T., Taniguchi, K., Komori, Y., Masuda, K., Fox, J.W., and Sugihara, H. (2000). Primary structure and functional characterization of bilitoxin-1, a novel dimeric P-II snake venom metalloproteinase from Agkistrodon bilineatus venom. Arch. Biochem. Biophys. 378, 6-15.

Nishida, S., Fujita, T., Kohno, N., Atoda, H., Morita, T., Takeya, H., Kido, I., Paine, M.J., Kawabata, S., and Iwanaga, S. (1995). cDNA cloning and deduced amino acid sequence of prothrombin activator (ecarin) from Kenyan Echis carinatus venom. Biochemistry 34, 1771-1778.

Reis, C.V., Protaro, F.C., Andrade, S.A., Fritzen, M., Fernandes, B.L., Sampaio, C.A., Camargo, A.C., and Chudzinski-Tavassi, A.M. (2001). A prothrombin activator serine protease from the Lonomia obliqua caterpillar venom (Lopap) biochemical characterization. Thromb. Res. 102, 427-436.

Rodrigues, V.M., Soares, A.M., Guerra-As, R., Rodrigues, V., Fontes, M.R., and Giglio, J.R. (2000). Structural and functional characterization of neuwiedase, a nonhemorrhagic fibrin(ogen)olytic metalloprotease from Bothrops neuwiedi snake venom. Arch. Biochem. Biophys. 381, 213-224.

Rosenfeld, G. (1971). Symptomatology, pathology and treatment of snake bites in South America. In: Venomous Animals and their Venoms, Vol. 2, W. Bucherl and E.E. Buckley, eds. (New York, USA: Academic Press), pp. 345-384.

Rosing, J. and Tans, G. (1992). Structural and functional properties of snake venom prothrombin activators. Toxicon 30 , 1515-1527. 
Rucavado, A., Lomonte, B., Ovadia, M., and Gutierrez, J.M. (1995). Local tissue damage induced by BaP1, a metalloproteinase isolated from Bothrops asper (Terciopelo) snake venom. Exp. Mol. Pathol. 63, 186-199.

Segrest, J.P. and Jackson, R.L. (1972). Molecular weight determination of glycoproteins by polyacrylamide gel electrophoresis in sodium dodecyl sulfate. Methods Enzymol. 28, 54-63.

Selistre, H.S., Dulce, H.F., and Ownby, C.L. (1997). Analysis of cDNA sequence encoding a novel member of the snake venom metalloproteases, disintegrin-like, cysteine-rich (MDC) protein family from Agkistrodon contortrix laticinctus. Biochim. Biophys. Acta 1342, 109-115.

Shimokawa, K., Shannon, J.D., Jia, L.G., and Fox, JW. (1997). Expression, activation, and processing of the recombinant snake venom metalloproteinase, pro-atrolysin E. Arch. Biochem. Biophys. 343, 35-43.

Siigur, E., Aaspollu, A., Tu, A.T., and Siigur, J. (1996). cDNA cloning and deduced amino acid sequence of fibrinolytic enzyme (lebetase) from Vipera lebetina snake venom. Biochem. Biophys. Res. Commun. 224, 229-236.

Silva, M.B., Schattner, M., Ramos, C.R., Junqueira-de-Azevedo, I.L., Guarnieri, M.C., Lazzari, M.A., Sampaio, C.A., Pozner, R.G., Ventura, J.S., Ho, P.L., and Chudzinski-Tavassi, A.M. (2003). A prothrombin activator from Bothrops erythromelas (jararaca-da-seca) snake venom: characterization and molecular cloning. Biochem. J. 369, 129-139.

Smith, C.W., Marlin, S.D., Rothlein, R., Toman, C., and Anderson, D.C. (1989). Cooperative interactions of LFA-1 and Mac1 with intercellular adhesion molecule-1 in facilitating adherence and transendothelial migration of human neutrophils in vitro. J. Clin. Invest. 83, 2008-2017.

Souza, C.T., Moura, M.B., Magalhaes, A., Heneine, L.G., Olortegui, C.C., Diniz, C.R., and Sanchez, E.F. (2001). Inhibition of mutalysin II, a metalloproteinase from bushmaster snake venom by human $\alpha_{2}$-macroglobulin and rabbit immunoglobulin. Comp. Biochem. Physiol. B Biochem. Mol. Biol. 130, 155-168.

Springer, T.A. (1994). Traffic signals for lymphocyte recirculation and leukocyte emigration: the multistep paradigm. Cell 76, 301-314.

Spronk, H.M.H., Govers-Riemslag, J.W.P., and Cate, H.T. (2003). The blood coagulation system as a molecular machine. Bioessays 25, 1220-1228.

Tsai, I.H., Wang, Y.M., Chiang, T.Y., Chen, Y.L., and Huang, R.J. (2000). Purification, cloning and sequence analyses for prometalloprotease-disintegrin variants from Deinagkistrodon acutus venom and subclassification of the small venom metalloproteases. Eur. J. Biochem. 267, 1359-1367.

Tseng, Y.L., Wu, W.B., Hsu, C.C., Peng, H.C., and Huang, T.F. (2004). Inhibitory effects of human $\alpha_{2}$-macroglobulin and mouse serum on the PSGL-1 and glycoprotein Ib proteolysis by a snake venom metalloproteinase, triflamp. Toxicon 43 , 769-777.

van de Stolpe, A. and van der Saag, P.T. (1996). Intercellular adhesion molecule-1. J. Mol. Med. 74, 13-33.

Watanabe, L., Shannon, J.D., Valente, R.H., Rucavado, A., Alape-Giron, A., Kamiguti, A.S., Theakston, R.D., Fox, J.W., Gutierrez, J.M., and Arni, R.K. (2003). Amino acid sequence and crystal structure of $\mathrm{BaP} 1$, a metalloproteinase from Bothrops asper snake venom that exerts multiple tissuedamaging activities. Protein Sci. 12, 2273-2281.

Yamada, D., Shin, Y., and Morita, T. (1999). Nucleotide sequence of a cDNA encoding a common precursor of disintegrin flavostatin and hemorrhagic factor HR2a from the venom of Trimeresurus flavoviridis. FEBS Lett. 451, 299-302.

Received November 10, 2004; accepted April 7, 2005 